ORIGINAL ARTICLE

\title{
Prevalence of Second Mesio-Buccal (Mb2) Canal in Permanent Maxillary First Molar
}

\author{
HUMA SARWAR ${ }^{1}$, MESHAL MUHAMMAD NAEEM ${ }^{2}$, SYED ALI RAZA ${ }^{3}$, SANAM FAHEEM ${ }^{4}$, AMIR AKBAR SHAIKH ${ }^{5}$, UJALA \\ MUSHTAQUE6 \\ ${ }^{1} B D S$ MDS Operative Dentistry, Lecturer Dept of Operative Dentistry, Dr Ishrat ul Ebad Khan Institute of Oral Health Sciences (DIKIOHS- \\ DUHS), Karachi \\ ${ }^{2}$ BDS MDS Resident, Lecturer Dept of Periodontology, Dr Ishrat ul Ebad Khan Institute of Oral Health Sciences (DIKIOHS-DUHS), Karachi \\ ${ }^{3}$ Senior Registrar, dept of Community Dentistry, Sir Syed College of Medical Sciences for Girls, Karachi \\ ${ }^{4} \mathrm{MSc}, \mathrm{BDS}$, Lecturer Oral Biology department, Dow Dental College, DUHS Karachi \\ ${ }^{5}$ BDS PG Dip. Dental Public Health, Associate Professor \& HOD Dept of Community Dentistry, Mohammed Dental College, Mirpur Khas \\ ${ }^{6}$ BDS M.Sc Periodontology, Assistant Professor \& HOD Dept of Periodontology, Jinnah Medical and Dental College, Karachi \\ Corresponding Author: Dr. Huma Sarwar, Email: huma.sarwar@duhs.edu.pk, Cell No.+923002552781
}

\begin{abstract}
Objective: The aim of this study is to determine the prevalence of second mesio-buccal canal in permanent maxillary first molars.

Study Design: Cross sectional study.

Place and Duration: Dr Ishrat ul Ebad Khan Institute of Oral Health Sciences, Karachi during the period from February 2020 to January 2021

Patients and Methods: Three hundred and fifty cases of both genders were presented in this study. Patients were aged between 18-60years. Patients' detailed demographics including age, sex and body mass index were recorded after taking written consent. Local anesthesia was given for isolation of rubber dam. The pulp chamber floor was clearly visualized and the access cavity was ready. The location of the MB2 channel in three phases was done. Complete data was analyzed by SPSS 22.0 version.

Results: Mean age of the patients were $30.14 \pm 17.47$ years with mean BMl $25.61 \pm 8.25 \mathrm{~kg} / \mathrm{m}^{2}$. Among $350 \mathrm{cases}$, Majority of the patients 225 (64.3\%) were male while the rest 125 (35.7\%) were females. Majority of the patients were from age group 20-30 years and less patients were between 51-60 years old. Frequency of second mesiobuccal canal was found in $280(80 \%)$ patients.

Conclusion: We concluded in this study that prevalence of MB2 channel was reported in $80 \%$ in the initially permanent maxillary molars. Most MB2 canal apertures are distal from the main MB channel and most MB2 apertures are palatal.

Key words: Permanent maxillary first molar, MB2 canals, Frequency
\end{abstract}

\section{INTRODUCTION}

Maxillary molar is also probably the post-moon tooth with the largest volume and most complex root and root canal structure. [1] The primary requirements for successful endodontic therapy are identifying and finding all spaces of root canals with the thorough preparation of chemomechanisms and achieving a hermetic seal with inert sealing material throughout the exit portal. [2,3] Anatomical voids in the root canal system which can operate as an infectious nest, causing treatment failures can be linked to a post treatment disease. [2] One of the greatest mysteries of endodontic activity is the elusive "second mesiobucal" (MB2) channel.

It has been revealed that the MB2 teeth retracted from endodonstick include a higher number of undiagnosed canals than the first time that the teeth are treated. [4] For maxillary molars, the second mesiobuchal orifice is normally placed on or off the main mesiobuchal canal and palatal canal mesially in the pulpary groove and in a distance of $3.5 \mathrm{~mm}$ palatially and 2 metric mesially from the main mesiobuchal canal.[5,6,7]

The tactile dexterity and mental image of the canal system have traditionally been used to detect most of the endodontic canal treatments, since it is extremely restrained to observe the channel orifices.[8] The surgical operating microscope(SOM) has made the location of the channels easier by magnifying and lighting the groves on the pulpal floor and separating the colors of the floor dentine from the walls. $[9,10]$

This study evaluated the possibility of increasing the identification of the second mesiobukal channels in the permanent maxillary first molars with the additional use of SOM and selective dentin removal.

\section{MATERIALS AND METHODS}

This cross-sectional study was conducted at Dr Ishrat ul Ebad Khan Institute of Oral Health Sciences, Karachi during the period from February 2020 to January 2021 and 350 patients were recruited in this study. Patients' demographics were recorded after obtaining written consent. Patients with maxillofacial surgery, insufficient periodontal support, calcified canals, caries extending to the floor of the pulp chamber was excluded.

Patients were aged between 18-60 years and belonging to diverse races with maxillary first permanent pulpal exposure patients requiring root canal treatment. After administration of local anesthetic, rubber dam for was placed. The positioning of the MB2 canal in three phases; (i) canals were located using an endodontic explorer (DG16) with naked eye. Canal was negotiated and confirmed with size $08 \mathrm{~K}$ file (Mani), (ii) further efforts to locate canals were examined with dental loupes $\times 3.5$ magnification for the presence of MB2. If MB2 was located with or without magnification, Size 6, 8, and $10 \mathrm{k}$-file was inserted in MB 
and MB2 canals. Complete data was analyzed by SPSS 20.0 version.

\section{RESULTS}

Mean age of the patients were $30.14 \pm 17.47$ years with mean BMI $25.61 \pm 8.25 \mathrm{~kg} / \mathrm{m}^{2}$. Among 350 cases, Majority of the patients $225(64.3 \%)$ were male while the rest 125 $(35.7 \%)$ were females. (table 1 )

Table 1: Baseline details demographics of enrolled cases

\begin{tabular}{|l|l|l|}
\hline Variables & Frequency $(\mathbf{n}=350)$ & \%age \\
\hline Gender & 225 & 64.3 \\
\hline Male & 125 & 35.7 \\
\hline Female & $30.14 \pm 17.47$ & - \\
\hline Mean age & $25.61 \pm 8.25$ & - \\
\hline Mean BMl &
\end{tabular}

Majority of the patients 175 (50\%) were from age group 1830 years followed by age group $31-40$ years 87 (24.86\%), $50(14.3 \%)$ were from age group 41-50 years and the rest were 38 (10.86\%) between 51-60 years.

Table 2: Distribution of cases with respect to age

\begin{tabular}{|l|l|l|}
\hline Variables & Frequency $(\mathbf{n}=\mathbf{3 5 0})$ & \%age \\
\hline Age group (years) & 175 & 50 \\
\hline $18-30$ & 87 & 24.8 \\
\hline $31-40$ & 50 & 14.3 \\
\hline $41-50$ & 38 & 10.9 \\
\hline $51-60$ & &
\end{tabular}

Frequency of second mesiobuccal canal was found in 280 $(80 \%)$ patients and not found in $70(20 \%)$ cases.(table 3$)$

Table 3: Prevalence of second mesiobuccal canal among permanent maxillary first molars

\begin{tabular}{|l|l|l|}
\hline Variables & Frequency $(\mathbf{n}=\mathbf{3 5 0})$ & \%age \\
\hline Second mesiobuccal canal (MB2) & \multicolumn{2}{|l|}{} \\
\hline Yes & 280 & 80 \\
\hline No & 70 & 20 \\
\hline
\end{tabular}

\section{DISCUSSION}

Canal identification is the first crucial stage in channel debridging. An important therapeutic problem is created by the high incidence of MB2 in maxillary molars which are often recognized and ignored during root canal treatment. $[12,13]$ In this cross sectional study 350 patients were presented. Majority of the patients were $64.3 \%$ were males and $35.7 \%$ were females. Mean age of the patients were $30.14 \pm 17.47$ years with mean BMl $25.61 \pm 8.25 \mathrm{~kg} / \mathrm{m}^{2}$. These findings were comparable to the previous study.[14] Majority of the patients 175 (50\%) were from age group 1830 years followed by age group $31-40$ years 87 (24.86\%), $50(14.3 \%)$ were from age group $41-50$ years and the rest were $38(10.86 \%)$ between $51-60$ years. These were relatable to the recent study.[15] A Weine et al[16] study found that MB2 incidents in Japanese populations were different from those of other ethnic backgrounds for MB2 Canals. A study by Weine et al[16]. In terms of age, the number of MB2 channels decreases most likely with age due to calcification. $[17,18]$

In current study frequency of second mesiobuccal canal was found among $80 \%$ cases in permanent maxillary first molar. Some clinical studies[19-21] and clinical simulation studies[22,23] in which MB2 channels were discovered in $>71 \%$ of the teeth may show a significant increase in prevalence. This significant rise was mainly caused by a better understanding of the presence of MB2 channels[8] and the change in the creation of an access cavity.[24] Two channels were more prevalent in laboratory investigations in mesiobuccal root (60.5 per cent) than in clinical trials (54.7 percent ). [24] In clinical research it was established that two MB channels comprise up to $93 \%$ of the first maxillary molars studied. [25]

Converse data from Sempira and Hartwell [26] revealed, though, that only 33 percent of maxillary first molars found the 2nd channel in mesiobuccal. Some research have evaluated the MB2 channel presence or absence outcomes in vivo with in vitro. In an in vivo study, Seidberg et al.[27] revealed that $33 \%$ of the teeth $(n=201)$ investigated possessed MB2 channels and in their in-vitro research the percentage was up to $62 \%(n=100) .31 \%$ of teeth tested in vivo had a second mesiobuccal channel in a research conducted by Pomeranz and Fishelberg, compared to $69 \%$ of teeth in vitro $(n=100$ for both investigations). [28]

Three major conclusions from the present study may be seen while identifying the association between the root shapes and the incidence of MB2: The predominantly oval (combined) root shape has been detected, which suggests that the roots of $\mathrm{MB}$ are largely oval, i.e. flat or ribbon. Long oval or oval root shape with MB2 canals was not a significant preference, but the incidence of MB2 in long oval root forms was substantially greater than the Oval one and in oval root forms.

Taking into account the foregoing data, the occurrence of MB2 channels can be determined to be in definite correlation with the root shape of the permanent maxillary root of the first molar.

The inexperience of observer, the interobserver difference of methodologies used to research root canal anatomy and the technical variances have their own part, and those aspects must always be taken into consideration throughout the conduct and reporting of such investigations. Anatomy is fate and the destiny is buried in endodontics. As a physician, we have to do all in our power to better understand and study the anatomy.

\section{CONCLUSION}

We concluded in this study that prevalence of MB2 channel was reported in $80 \%$ in the initially permanent maxillary molars. Most MB2 canal apertures are distal from the main MB channel and most MB2 apertures are palatal.

\section{REFERENCE}

1. Burns RC. 8th ed. St Louis, Mo, USA: The Mosby Co; 2002. Access openings and tooth morphology: Cohen's pathways of pulp; pp. 173-229.

2. Schilder H. Cleaning and shaping the root canal. Dent Clin North Am. 1974;18:269-96.

3. Hess W, Zurcher E. London: John Bane, Sons and Danielsson Ltd; 1925. The Anatomy of the Root Canals of the Teeth of the Permanent Dentition; pp. 4-49.

4. Wolcott J, Ishley D, Kennedy W, Johnson S, Minnich S. Clinical investigation of second mesiobuccal canals in endodontically treated and retreated maxillary molars. J Endod. 2002;28:477-9.

5. Cantatore G, Berutti E, Castellucci A. Missed anatomy: Frequency and clinical impact. Endod Top. 2009;15:3-31. 
6. Pomeranz HH, Fishelberg G. The secondary mesiobuccal canal of maxillary molars. J Am Dent Assoc. 1974;88:119-24.

7. Kulild JC, Peters DD. Incidence and configuration of canal systems in the mesiobuccal root of maxillary first and second molars. J Endod. 1990;16:311-7.

8. Hartwell G, Bellizi R. Clinical investigation of in vivo endoodtically treated mandibular and maxillary molars. J Endod. 1982;8:555-7.

9. Kim S, Baek S. The microscope and endodontics. Dent Clin North Am. 2004;48:11-8.

10. Carr GB, Murgel CA. The use of the operating microscope in endodontics. Dent Clin North Am. 2010;54:191-214.

11. Aqwa AS, Sheikh Z, Rashid H. Canal configuration and the prevalence of second mesiobuccal canal in maxillary first molar of a saudi sub-population. J Pak Dent Assoc 2015; 24(4):182-187.

12. Howait M, Al-Habib M. Assessment of Mesiobuccal Canal Configuration, Prevalence and Inter-Orifice Distance at Different Root Thirds of Maxillary First Molars: A CBCT Study. Clin Cosmet Investig Dent. 2021;13:105-111

13. Weine F, Hayami S, Hata G, Toda T. Canal configuration of the mesiobuccal root of the maxillary first molar of a Japanese sub?population. Int Endod J. 1999;32(2):79-87

14. Neaverth EJ, Kotler LM, Kaltenbach RF. Clinical investigation (in vivo) of endodontically treated maxillary first molars. J endod. 1987;13(10):506-512

15. Sempira H, Hartwell G. Frequency of second mesiobuccal canals in maxillary molars as determined by use of an operating microscope: a clinical study. J endod. 2000;26(11):673-674.

16. Cleghorn BM, Christie WH, Dong CC. Root and root canal morphology of the human permanent maxillary first molar: A literature review. J Endod. 2006;32:813-21.

17. Stropko JJ. Canal morphology of maxillary molars: Clinical observations of canal configurations. J Endod. 1999;25:44650

18. Das S, Warhadpande MM, Redij SA, Jibhkate NG, Sabir H. Frequency of second mesiobuccal canal in permanent maxillary first molars using the operating microscope and selective dentin removal: A clinical study. Contemp Clin Dent. 2015;6(1):74-78. doi:10.4103/0976-237X.149296

19. Ibarrola JL, Knowles KI, Ludlow MO, McKinley IB., Jr Factors affecting the negotiability of second mesiobuccal canals in maxillary molars. J Endod. 1997;23:236-8.

20. Imura N, Hata GI, Toda T, Otani SM, Fagundes MI. Two canals in mesiobuccal roots of maxillary molars. Int Endod J. 1998;31:410-4.

21. Fogel HM, Peikoff MD, Christie WH. Canal configuration in the mesiobuccal root of the maxillary first molar: A clinical study. J Endod. 1994;20:135-7.

22. Stropko JJ. Canal morphology of maxillary molars: clinical observations of canal configurations. $\mathrm{J}$ endod. 1999;25(6):446-450.

23. Sempira H, Hartwell G. Frequency of second mesiobuccal canals in maxillary molars as determined by use of an operating microscope: a clinical study. J endod. 2000;26(11):673-674

24. Seidberg BH, Altman M, Guttuso J, Suson M. Frequency of two mesiobuccal root canals in maxillary permanent first molars. J Am Dent Assoc. 1973;87(4):852856.

25. Pomeranz HH, Fishelberg G. The secondary mesiobuccal canal of maxillary molars. J Am Dent Assoc. 1974;88(1):119124. 